\title{
MULTISTAGE GRAVITY BENEFICIATION OF RUTILE IN A TAR-FREE SAND RESIDUE
}

\author{
Rukayat AKANdE*1 ANd Abraham AdELEKE ${ }^{1}$ \\ ${ }^{1}$ Department of Materials Science and Engineering, Obafemi Awolowo University, lle-Ife, Nigeria
}

\begin{abstract}
This study reports on the concentration of rutile in the sand recovered from tar sand in Ondo State in Nigeria. The tar-free sand residue, approximately $90 \%$ of which passes through a sieve with a pore size of $355 \mu \mathrm{m}$, was subjected to sieve analysis as well as sequences of panning gravity pre-concentration and shaking-table concentration at a slurry density of $25 \%$ solids to improve the rutile content. The sand residue recovered in addition to the panned pre-concentrate and shaking table concentrates were also subjected to reflected light microscopy as well as transmitted light microscopy, counting using ImageJ software and X-ray fluorescence spectroscopy. The micrographs obtained showed that the samples contain rutile, dark-brown in color, interlocked with the major silica content and the content of rutile estimated by ImageJ software increased in the pre-concentrate from $7.90 \%$ to $19.23 \%$ in the final concentrate. X-ray fluorescence spectroscopy also showed that the rutile content increased in the pre-concentrate from $1.43 \%$ to $31.02 \%$ in the final concentrate. Therefore, the rutile content was successfully increased by the cheap gravity techniques of panning and shaking tables.
\end{abstract}

Keywords: Tar sand, rutile, panning, shaking table, pre-concentrate, concentrate

\section{Introduction}

Tar sands, also known as oil sands, are a combination of clay, sand and water saturated in a dense and extremely viscous form of petroleum technically referred to as bitumen. Tar sands are impregnated sands that yield mixtures of liquid hydrocarbons, which require further processing other than mechanical blending before becoming finished petroleum products. Tar sand deposits are found in various parts of the world including Canada, Madagascar, Venezuela, Russia, the United States and Nigeria [1]. Tar sand is exceedingly rich in oil as well as other valuable minerals and metals in varying proportions [2]. Tar sand deposits are composed primarily of quartz sand, silt, clay, water and bitumen along with trace amounts of metallic minerals such as rutile, pyrite, zircon and gemstones like tourmaline. Rutile is a major source of the element titanium and it is industrially used as a white pigment for paint, a ceramic glaze and in optical equipment $[3,4]$. It is also used in sunscreen products due to its ability to reflect ultraviolet light [5].

Nigeria has a large deposit of natural bituminous tar sand, which is estimated to be the fourth largest in the world after Canada, Russia and Venezuela [6]. It is estimated that about 34 to 45 billion barrels of heavy oil is trapped in tar sand deposits in Ondo State in Southwestern Nigeria alone, with more reserves in Edo and Ogun States. The reserve of tar sand in Ondo State alone is es-

\footnotetext{
*Correspondence: akanderukayat2@gmail.com
}

timated to be 31 billion metric tons [7]. The tar sand here is located in the eastern part of the Dahomey Basin, a coastal sedimentary basin that extends from the GhanaIvory Coast border through Togo and the Republic of Benin to Western Nigeria [8].

Adeleke et al. [9] leached tar sand from Ondo State using sodium hydroxide and sodium carbonate to strip off bitumen from the admixture of sand and also conducted a solubility test on the tar sand using toluene. Sodium hydroxide was found to yield a higher percent recovery of bitumen than sodium carbonate over the same leach contact time. Adebiyi et al.[10] determined the elemental composition of oil sand from Southwestern Nigeria by Total Reflection X-ray Fluorescence and detected twelve elements, namely $\mathrm{K}, \mathrm{Ca}, \mathrm{Ti}, \mathrm{V}, \mathrm{Cr}, \mathrm{Mn}, \mathrm{Fe}, \mathrm{Ni}, \mathrm{Cu}, \mathrm{Zn}$, As and $\mathrm{Pb}$. Ignasiak [11] reported that a Nigerian deposit of bitumen-free sand residue contains only $0.06 \mathrm{wt} \% \mathrm{TiO}_{2}$.

Gravity beneficiation techniques make use of the difference in the specific gravity of minerals to separate them. Therefore, heavy minerals such as rutile can be separated from the associated lighter minerals like silica. In the gravity method of shaking tables, a flowing film of water effectively separates coarse light particles from small dense particles [12]. Mixed rutile and ilmenite ores were subjected to coarse concentration using a mineral jig [13].

In this research, the lean content of the mineral rutile in a residue of tar sand from Ondo was increased over a sequence of gravity beneficiation by panning and shaking 
tables.

\section{MATERIALS AND METHODS}

\subsection{The Collection of Samples}

The basic raw materials used in this work were lumps of bituminous tar sand obtained from Ondo State, Nigeria. Lumps of the semi-solid black tar sand of about 50 $\mathrm{kg}$ in weight were collected from the villages of Agbabu and Loda in the Local Government Area of Irele in Ondo State. The Local Government Area of Irele is situated to the east of the Local Government Area of Okitipupa which lies at $40^{\circ} 3^{\prime \prime}$ in longitude east of the Greenwich meridian and at $50^{\circ} 45^{\prime}$ and $80^{\circ} 15^{\prime}$ in latitude north of the equator. The samples were collected from two open pits at a depth of about 3 feet. After field sampling, the lumps of tar sand extracted were stored in large plastic bags.

\subsection{Sample preparation}

The black lumps of tar sand were crushed and ground thoroughly with a steel rod. The ground tar sand was then homogenized in a mortar by pounding it with a pestle. The resultant mass of tar sand was composed of a finer mixture of particles and bitumen.

\subsection{Stripping of bitumen by leaching whilst being stirred}

The tar sand was leached on a magnetic hotplate stirrer using a $3^{2}$ factorial design, that is, at three different temperatures and by applying variables concerning the concentration process. The $250 \mathrm{ml}$ beaker reactor containing the slurry of tar sand and $25 \mathrm{ml}$ of $0.5 \mathrm{M}$ sodium hydroxide at a pulp density of approximately $40 \mathrm{~g} / \mathrm{L}$ was initially homogenized for 5 minutes. The beaker was placed on a Stuart magnetic hotplate stirrer, model number R000101019, which was set to $50{ }^{\circ} \mathrm{C}$ and $90 \mathrm{rpm}$ to yield the $\mathrm{T}_{1} \mathrm{C}_{1}$ test combination. The magnetic stirrer was switched on and the pulp of tar sand allowed to react with the leachant, sodium hydroxide, for $30 \mathrm{~min}$ utes. After 30 minutes, the concentrate of bitumen was skimmed off and the leachant filtered to remove the remaining bitumen. The procedure was repeated for combinations $\mathrm{T}_{1} \mathrm{C}_{2}, \mathrm{~T}_{1} \mathrm{C}_{3}, \mathrm{~T}_{2} \mathrm{C}_{1}, \mathrm{~T}_{2} \mathrm{C}_{2}, \mathrm{~T}_{2} \mathrm{C}_{3}, \mathrm{~T}_{3} \mathrm{C}_{1}, \mathrm{~T}_{3} \mathrm{C}_{2}$, and $\mathrm{T}_{3} \mathrm{C}_{3}$.

\subsection{Stripping of bitumen by leaching in the ab- sence of stirring}

A slurry of tar sand with a pulp density of approximately $40 \mathrm{~g} /$ litre was prepared by mixing $25 \mathrm{ml}$ of $1.5 \mathrm{M}$ sodium hydroxide and $1 \mathrm{~g}$ of tar sand in a $500 \mathrm{ml}$ beaker. The beaker containing the slurry of tar sand was then placed on a HP-11electric hot plate. The slurry was stirred continuously for 30 minutes with a glass rod to agitate it to facilitate the recovery of bitumen from the tar sand. Subsequently, the bitumen was decanted off and the residue washed with water to remove the bitumen. The residue was washed again with toluene to dissolve traces of bitumen in the tailings. The residue was then dried at $70{ }^{\circ} \mathrm{C}$ in an oven and the procedure repeated using $20,3,4,5$, $6,7,8,9$, and $10 \mathrm{~g}$ of tar sand which resulted in pulp densities of approximately 80, 120, 160, 200, 240, 280, 320, 360 , and $400 \mathrm{~g} / \mathrm{L}$, respectively. The same procedure was repeated using $30 \mathrm{~g}$ of tar sand and the slurry prepared by mixing $300 \mathrm{ml}$ of $1.5 \mathrm{M}$ sodium hydroxide and $30 \mathrm{~g}$ of tar sand in a $500 \mathrm{ml}$ beaker. The procedure was repeated several times until $7 \mathrm{~kg}$ of tar-free sand was recovered.

A blank test was conducted using $25 \mathrm{ml}$ of distilled water and $1 \mathrm{~g}$ of tar sand in a $500 \mathrm{ml}$ beaker reactor. The beaker containing the slurry of tar sand was then placed on the HP-11 electric hot plate. The slurry was stirred continuously with a glass rod to agitate it to facilitate the recovery of bitumen from the tar sand.

\subsection{Panning of the tar-free sand}

About $50 \mathrm{~g}$ of the sample was thoroughly mixed and agitated with $50 \mathrm{ml}$ of water in a $500 \mathrm{ml}$ plastic bowl. The panning process caused the lighter mineral particles to float while the denser particles sank. The floating light particles were decanted off while the denser residue was dried and weighed. The procedure was repeated but with $100,150,200,250,300$, and $350 \mathrm{ml}$ of water.

Following preliminary panning, the remaining sample that weighed $36.25 \mathrm{~g}$ was subjected to further panning using the same $350 \mathrm{ml}$ of water. The procedure was repeated ten more times by weighing the wet residue together with a content of $4.02 \mathrm{~g}$ after each panning. The same procedure was employed for the shaking tabling of approximately $138 \mathrm{~g}$ of the sample. $966 \mathrm{ml}$ of water was used for panning the $138 \mathrm{~g}$ of tar-free sand ten times and the final product weighed and dried before proceeding to the shaking table.

\subsection{Determination of the specific gravity of tar-free sand}

A density bottle was washed, dried and its weight, $m_{1}$, measured. Subsequently, $5 \mathrm{~g}$ of tar-free sand residue was placed inside the dried bottle and its weight, $m_{2}$, determined. Then, $50 \mathrm{ml}$ of distilled water was poured into a measuring cylinder and weighed to give $m_{4}$. Lastly, distilled water was added to the tar-free sand in a covered bottle and shaken very well for thorough mixing, moreover, additional distilled water was added to increase the volume to $50 \mathrm{ml}$ and then weighed to give $m_{3}$. To determine the specific gravity, thsese values were inserted into equation [12]

$$
G=\frac{m_{2}-m_{1}}{\left(m_{4}-m_{1}\right)-\left(m_{3}-m_{2}\right)}
$$

where $m_{1}$ is the mass of empty bottle, $m_{2}$ is the mass of bottle + dry soil, $m_{3}$ is the mass of bottle + dry soil + 


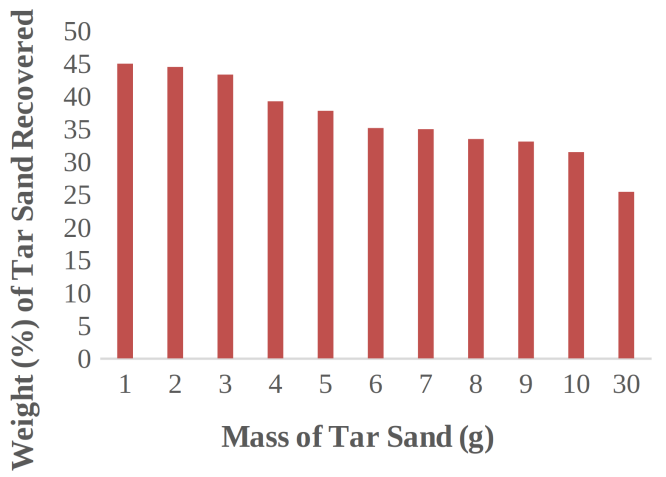

Figure 1: Weight percentage of tar sand recovered following stripping on an electric hot plate.

water, and $m_{4}$ is the mass of bottle filled with water only. After deriving the specific gravity, the ratio of solids to water required to make the slurry was also determined as the feed should be composed of about $25 \%$ solids by weight.

\subsection{Shaking tabling}

A slurry composed of $25 \%$ solids by weight was produced by mixing $108 \mathrm{~g}$ of the panned sample in $324 \mathrm{ml}$ of water which was introduced via the feed box of a shaking table, model number ED808148566Q. The slurry was distributed evenly over the table, wash water was dispersed along the balance length of the feed launder. The table was then vibrated longitudinally using a slow forward stroke and a rapid return strike which caused the mineral particles to 'crawl' along the deck parallel to the direction of motion. As a result, the minerals were subjected to two forces, one due to the motion of the table and the other at right angles to it due to the flowing film of water.

Consequently, the particles moved diagonally across the deck from the feed end and fanned out on the table - the smaller, denser particles rode on top towards the concentrate launder at the far end. The larger lighter particles were washed into the tailings launder, which runs along the length of the table. An adjustable splitter at the concentrate launder was used to separate the product into three fractions, namely a high-grade concentrate and two medium-grade fractions. The concentrate continued to be shaken nine more times and the products weighed wet after every shaking. The final products were dried separately and then weighed [12].

\subsection{Particle size analysis using a sieving method}

The eight sieves with pore sizes of between 850 and 63 $\mu \mathrm{m}$ were chosen based on the square root of two rule. The weights of the empty sieves were recorded and stacked on top of each other with the coarsest sieve with a pore size of $850 \mu \mathrm{m}$ on the top and the finest of $63 \mu \mathrm{m}$ at the bottom. A fitting receiver was placed below the bottom sieve to collect any undersized particles and a lid placed on top of the coarsest sieve to prevent the sample from escaping. Fig. 1 shows the sieving machine and the setup of the sieves. A $300 \mathrm{~g}$ sample of the recovered tar-free sand was poured onto the uppermost, coarsest sieve, and the nest of sieves placed in an Endecotts test sieve shaker, model number 9205. The nest of sieves was vibrated in a vertical plane. The period of shaking was set to $30 \mathrm{mins}$ using an automatic timer. During the shaking, the undersized material dropped through successive sieves until it was retained on a sieve with a pore size slightly smaller than the diameter of the particles. In this way, the sample was separated into size fractions. After the required time, the nest of sieves was dismantled and the amount of material retained on each sieve weighed [12].

\subsection{Reflected light microscopy}

The sample was deposited on a slide which was placed on the stage of an ACCU-SCOPE microscope, serial number 0524011. The diaphragm was then used to vary the intensity and size of the cone of light that was projected upwards through the slide. The microscope was connected to a laptop to capture the plane section of the image which was captured using image capture software on a laptop as soon as a clear image was obtained. Reflected light microscopy was used to view the raw sample, panned sample, samples obtained from the particle size analysis and those from the shaking table. ImageJ was used to analyze the images obtained from reflected light microscopy.

\subsection{Thin section microscopy}

The sample was impregnated since it was a loose sample by mixing equal amounts of araldite (resin and hardener) and sample together which was placed on a glass slide. The glass slide was placed on a hot plate for 5 mins and left to cool overnight. The cooled glass slide was ground by a lapping machine, transferred to a lapping plate for further grinding and viewed intermittently several times under the microscope till it became thin enough for light to penetrate through. The glass slide was dried on the hot plate, covered in araldite and viewed under a Brunel petrographic microscope, model no. 1287599.

\subsection{X-ray Fluorescence spectroscopy}

A $3 \mathrm{~g}$ sample was pulverized into a fine homogenous mass and pelletized. An X-ray fluorescence spectrometer, model no. EDX3600B, was used to analyze the sample. The desired method was selected on the measuring instrument and the sample carefully placed onto the instrument according to the set-up of its benchtop measurement position. The compartment containing the sample was covered to prevent $\mathrm{X}$-ray radiation from being scattered. The measurement conditions were set, the details of the sample entered and the complete spectrum recorded which 
Table 1: Screened distribution of sand recovered from tar sand.

\begin{tabular}{cccccc}
\hline $\begin{array}{c}\text { Pore-size } \\
\text { range of } \\
\text { sieve }(\mu \mathrm{m})\end{array}$ & $\begin{array}{c}\text { Weight of } \\
\text { sieve } \\
\text { fraction }(\mathrm{g})\end{array}$ & $\begin{array}{c}\text { Weight of } \\
\text { sieve } \\
\text { fraction }(\%)\end{array}$ & $\begin{array}{c}\text { Nominal } \\
\text { aperture } \\
\text { size }(\mu \mathrm{m})\end{array}$ & $\begin{array}{c}\text { Cumulative } \\
\text { Undersize } \\
\text { Distribution }(\%)\end{array}$ & $\begin{array}{c}\text { Cumulative } \\
\text { Oversize } \\
\text { Distribution }(\%)\end{array}$ \\
\hline+850 & 1.02 & 0.37 & 850 & 99.63 & 0.37 \\
850 to +500 & 0.92 & 0.33 & 500 & 99.26 & 0.74 \\
500 to +355 & 5.05 & 1.84 & 355 & 97.45 & 2.55 \\
355 to +212 & 20.44 & 7.45 & 212 & 89.97 & 10.03 \\
212 to +150 & 178.7 & 65.14 & 150 & 24.86 & 75.14 \\
150 to +125 & 50.51 & 18.41 & 125 & 6.45 & 93.55 \\
125 to +90 & 16.62 & 6.06 & 90 & 0.39 & 99.61 \\
90 to +63 & 0.96 & 0.35 & 63 & 0.04 & 99.96 \\
$<63$ & 0.11 & 0.04 & & & \\
\hline
\end{tabular}

lasted 60 to 120 seconds per sample, moreover, all detectable elements were measured simultaneously. Raw quantitative spectra and quantified results were acquired and saved.

\section{RESULTS AND DISCUSSION}

It can be seen from Fig. 1 that the weight percent of recovered tar-free sand reduces as the mass of the tar sand increases which indicates that the percent recovery decreases as the pulp density increases. Therefore, pulp density is one of the factors that affects leaching, hence the laboratory-scale leaching of about $40 \mathrm{~g} / \mathrm{L}$ was conducted. The decrease in the leaching rate as the pulp density increases is due to increased particle crowding and a lower concentration of leachant available per unit volume of the slurry [14]. It was observed that the smallest bitumen recovery of $55 \%$ obtained from stirred leaching on the magnetic stirrer hotplate was greater than the highest recovery of $45 \%$ for the unstirred leaching on the ordinary hotplate. This confirms that slurry stirring is an important process variable in the hydrometallurgical approach to leaching [14].

The sieve analysis showed that the majority of the sample was found within the 212 to $150 \mu \mathrm{m}$ pore-size range, namely $65.14 \%$ of the sample. The results obtained suggest that the residue of the tar sand is fairly coarse as the fraction smaller than $63 \mu \mathrm{m}$ is insignificant. Coarse-sized ores are preferred for gravity concentration as they are more efficiently treated than finer ones [12]. The results are presented in Table 1 .

The lighter minerals from the $350 \mathrm{ml}$ volume of water were further reduced following nine sequential pannings. The residue obtained after ten sequential pannings was found to contain many of the denser minerals given that the majority of the lighter minerals had been previously removed as shown in Table 2 . This table shows that the mass of the denser sand residue obtained after panning generally decreased as the volume of water used for panning increased. The results obtained suggest that panning efficiency increases as the volume of water increases. This may be due to the fact that by increasing
Table 2: The recovery of denser materials as a function of the volume of water used during panning.

\begin{tabular}{ccc}
\hline Volume $(\mathrm{ml})$ & Residue $(\mathrm{g})$ & Mass recovered $(\%)$ \\
\hline 50 & 47.43 & 94.86 \\
100 & 45.42 & 90.84 \\
150 & 45.38 & 90.76 \\
200 & 44.01 & 88.02 \\
250 & 40.18 & 80.36 \\
300 & 38.63 & 77.26 \\
350 & 36.25 & 72.5 \\
\hline
\end{tabular}

the water content, a more dilute slurry subject to less particle crowding, a better degree of free flow and settling of mineral particles is produced, thus enhancing the separation of lighter particles from denser ones.

Fig. 2 indicates that generally the mass of denser residues decreased as the sequence of panning stages progressed. The results suggest that as the sequence of panning advances, the minerals composed of denser particles are progressively concentrated into the concentrates of denser residues [12].

It was observed from Fig. 3 that the more the shaking table charge was subjected to a sequence of shaking tabling, the greater the proportion of denser rutile that was separated from the lighter silica mineral. The weight of the dry concentrates and tailings obtained after the se-

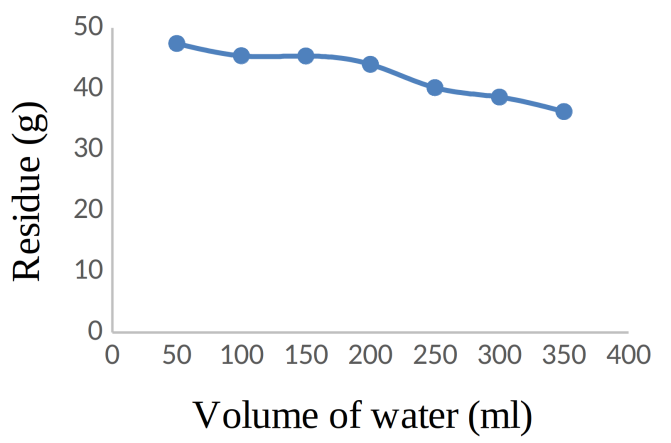

Figure 2: Residue obtained after panning the sand residue with various volumes of water. 
Table 3: Summary of the numbers of total and rutile counts as well as the estimated percentage of the raw and panned samples in addition to the concentrates and tailings from the shaking table obtained from the XRF spectroscopy of each sample.

\begin{tabular}{ccccc}
\hline Type of sample & Total count & Rutile count & $\begin{array}{c}\text { ImageJ } \\
\text { estimated } \\
\% \text { of rutile }\end{array}$ & $\begin{array}{c}\text { The \% of rutile } \\
\text { by XRF } \\
\text { spectroscopy }\end{array}$ \\
\hline $\begin{array}{c}\text { Raw sand residue } \\
\text { Panned sand residue }\end{array}$ & 1265 & 192 & 7.9 & 1.43 \\
$\begin{array}{c}\text { Shaking table concentrate of } \\
\text { sand residue }\end{array}$ & 1061 & 192 & 10.04 & 17.5 \\
$\begin{array}{c}\text { Shaking table tailings of } \\
\text { sand residue }\end{array}$ & 2041 & 99 & 19.23 & 31.02 \\
\hline
\end{tabular}

quence of ten shaking tablings of the charge were 10.55 and $48.29 \mathrm{~g}$, respectively. This figure shows that the mass of the concentrates of denser particles recovered generally decreased while that of the tailings increased with some minor exceptions. The results obtained confirm the concentration of rutile in the concentrate increased as the sequence advanced. The sequential stages of shaking progressively improved the grade of the concentrates in terms of denser minerals.

The plane-polarized and cross-polarized images obtained from reflected light microscopy and thin section microscopy of the raw and panned samples, in addition to the concentrate and tailings from the shaking table were analyzed. According to Francis [15], rutile was translucent and dark red-brown in color, while silica was transparent and whitish in color under a thin section microscope. Further observations showed that pure crystalline rutile was not abundant in the sample as most of the rutile under cross-polarized light was observed to be interlocked with silica. The plates further indicated that the rutile content of the concentrate on the shaking table exceeded that of the panned concentrate. A summary of the number of total and rutile counts as well as the percent distribution estimated for the raw and panned samples in addition to the concentrates and tailings of the shaking table is shown in Table 3. ImageJ counting estimated the rutile content in the recovered sand residue as well as in the concentrates of the shaking table and following pan-

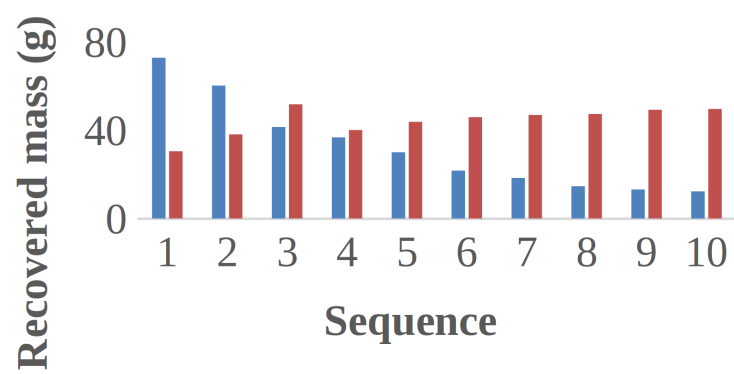

\section{Concentrate (g) $\square$ Tailings (g)}

Figure 3: Recovered masses of concentrates and tailings from ten sequential shaking tables. ning as $7.9,19.23$ and $10.04 \%$, respectively.

Fig. 4 shows the results from the X-ray fluorescence spectroscopy of the recovered and panned sand residues in addition to the concentrates from the shaking table. The percentage of silica in the recovered sand residue was reduced from $49.9 \%$ to $47.6 \%$ in the panned preconcentrate and further to $41.4 \%$ in the concentrate of the shaking table. Moreover, the titanium content of the recovered sand residue was enhanced from $0.86 \%$ to $10.6 \%$ in the panned pre-concentrate, while that of the concentrate from the shaking table in the panned preconcentrate was further improved to $18.3 \%$. Therefore, the results obtained showed that the rutile content of the recovered sand residue was enhanced from $1.43 \%$ to $17.50 \%$ in the panned concentrate and finally to $31.02 \%$ in the concentrate from the shaking table. The decrease in the silica content and increase in the titanium content strongly suggest that the panning and shaking table were efficient methods to improve the rutile content of the residue of tar sand. The results obtained from ImageJ counting also compare favorably with that of XRF spectroscopy except for the sample as received where both appeared to be significantly different. The flow diagram of the beneficiation process is shown in Fig. 5.

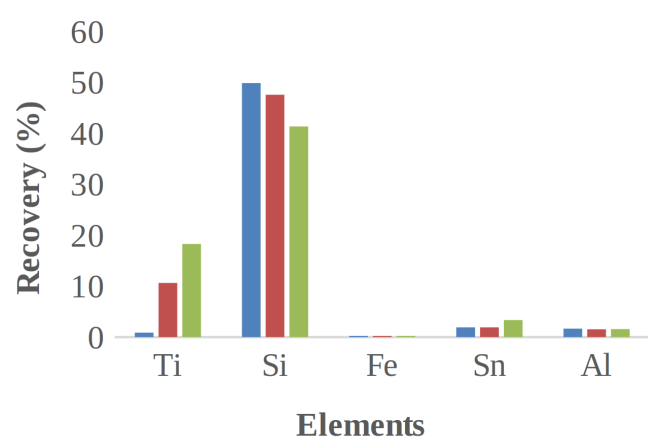

$$
\text { Original sample } \quad \text { Panned Sample }
$$

Figure 4: Percent recoveries of the elements Ti, Si, Fe, Sn and $\mathrm{Al}$ in the concentrates. 


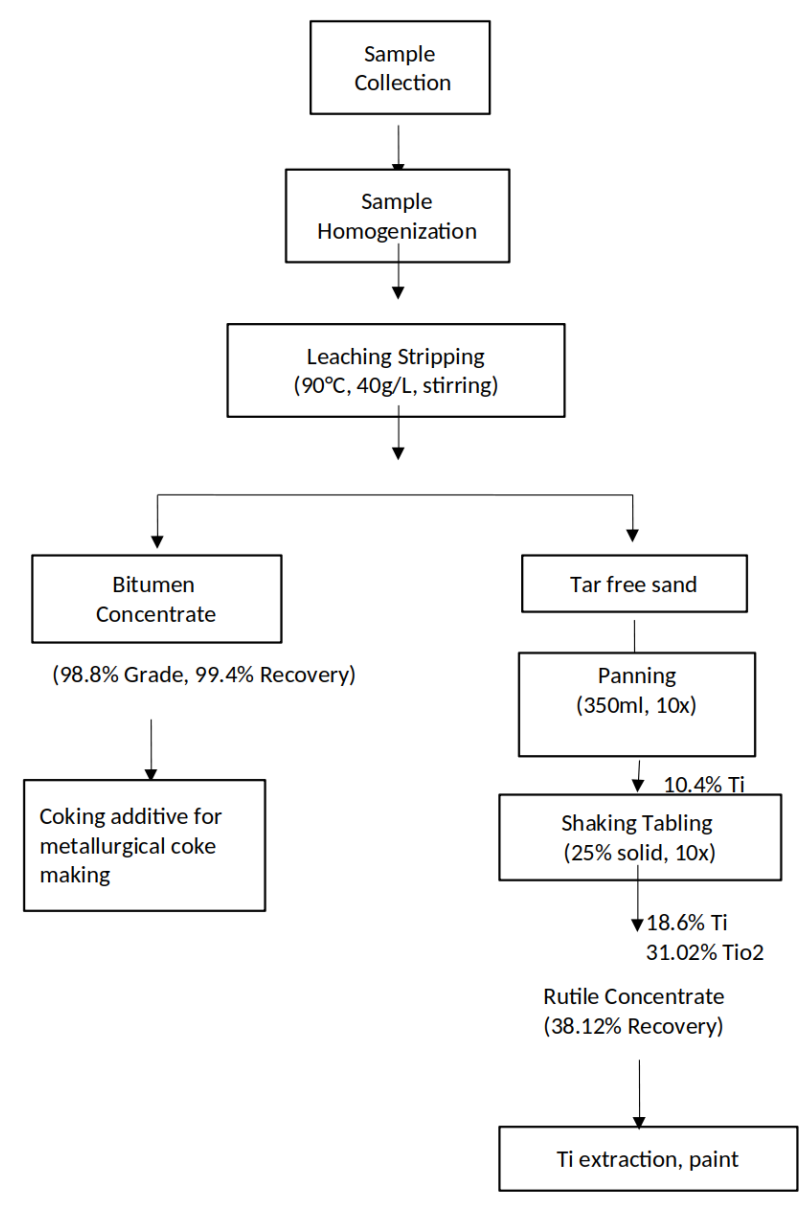

Figure 5: Flow diagram of the Bench-scale Beneficiation of Tar Sand from Ondo.

\section{Conclusions}

The rutile content of the tar-free residue obtained from tar sand extracted from Ondo was successfully improved by gravity beneficiation of the sand residue. The results obtained show that a sequence of panning preconcentrations followed by a sequence of shaking tabling improved the rutile content from $1.43 \%$ to $31.02 \%$.

\section{REFERENCES}

[1] Falebita, O. A.; Koul, S.: Sustainable development of oil sands and host communities: preliminary system dynamics assessment. (Managing Intellectual Capital and Innovation for Sustainable and Inclusive Society: Proceedings of the MakeLearn and TIIM Joint International Conference 2, ToKnowPress, 2015), pp. 2095-2109

[2] Allen, C.: Mineralogy of Tar Sand in the Upper Part of the Green River Formation in the Eastern Utah Basin, Utah. U.S. Geological Survey Open-file Report 76-381, pp. 27.
[3] Erdogan, L. Dielectric Properties of Oil sands at $2.45 \mathrm{GHz}$ Determined with Rectangular Cavity Resonator. M.Sc. Thesis, Université de Montréal, Montréal, QC, Canada. https://publications.polymtl.ca/732/1/2011_leventErdogan.pdf Retrieved on 12 November 2019

[4] Lavat, A. E.; Gayo, G. X.: New Environmental Friendly Yellow Ceramic Pigments of the Type (Fe111MV)-Ti02. J. Chem. Chem. Eng. 2014 8: 1026-1035 DOI: 10.17265/1934-7375/2014.11.003

[5] Reddy, K. M.; Manorama, S. V.; Reddy, A. R.: Bandgap studies on anatase titanium dioxide nanoparticles. Mat. Chem. Phys. 2003 78(1): 239245 DOI: 10.1016/s0254-0584(02)00343-7

[6] Adegoke, O. S.; Ako, B. D.; Enu, E. I.: Geotechnical Investigations of the Ondo State Bituminous Sands, Geology and Reserves Estimate. Unpublished manuscript. Department of Geology, Obafemi Awolowo University, Ile-Ife, Nigeria.

[7] Emmanuel, E.; Ajibade, O. M.: Elemental Composition and Geochemistry of Heavy Oil in Parts of Eastern Dahomey Basin, Southwestern Nigeria. $J$. Env. Earth Sci. 2014 4(12): 18-25

[8] Enu, E. I.: Textual Characteristics of the Nigeria Tar Sands. Sedimentary Geology, 44: 65-81. DOI: 10.1016/0037-0738(85)90032-6

[9] Adeleke, A. A.; Ibitoye, S. A.; Oladokun, C. B.; Oluwasegun, K. M.: An Evaluation of the Hot Aqueous Caustic Leaching of Nigerian Ondo Tar Sand. Petroleum and Coal, 2011 53(4): 320-323

[10] Adebiyi, F. M.; Asubiojo, O. I.; Ajayi, T. R.; Obiajunwa, E. I.: Trace element and physico-chemical characteristics of the sand and water fractions of Nigerian bituminous sands. Chemistry and Ecology, 2005 21(5): 369-380 DOI: 10.1080/02757540500291725

[11] Ignasiak, A. K.: Microscopic Structure of Athabasca Oil Sand. Can. J. Chem. Eng., 0982 60(4): 538-545 DOI: 10.1002/cjce.5450600416

[12] Wills, B. A., Napier-Munn, T.: Mineral processing technology (Elsevier, 2015) ISBN: 978-0-08-097053-0

[13] 911 Metallurgist. Metallurgists \& Mineral Processing Engineers. https://www.911metallurgist.com Retrieved on 25 August 2018

[14] Ghosh, A.; Ray, H. S.: Principles of extractive metallurgy. (New Age International, 1991) ISBN: 9788122403220

[15] Francis, C.: Characterization and Upgrading of a Rutile Concentrate Produced from the Oil Sands Tailings. M.Sc. Thesis, University of Alberta, Edmonton, AB, Canada, pp. 95-96. https://era.library.ualberta.ca/items/79044641-a67d410f-b072-4bf5b4cadb0d/view/f051e5bd-3406-4262-abc8dd479e66f11a/MQ81377.pdf Retrieved on 12 November 2019 